\title{
Redesigning Comprehensive Library Tutorials
} Theoretical Considerations for Multimedia Enhancements and Student Learning

\section{B. Jane Scales, Erica Nicol, and Corey M. Johnson}

\section{B. Jane Scales (scales@wsu.edu) is Electronic Projects Librarian, Erica Nicol (eacarlson@wsu.edu) is Subject Liaison Librarian, and Corey M. Johnson (coreyj@wsu. edu) is Head of Library Instruction Team, Washington State University, Pullman, Washington.}

Reference \& User Services Quarterly, vol. 53, no. 3, pp. 242-52

(c) 2014 American Library Association. All rights reserved.

Permission granted to reproduce for nonprofit, educational use.
When the Washington State University Library Instruction Team undertook a complete redesign of its two most central online tutorials, the task to incorporate multimedia challenged us to adopt newer pedagogical models into our information literacy curriculum. Drawing from several recent designs and learning theories, including cognitive load, Mayer's theory of multimedia learning, Anderson's theory of ACT-R cognitive architecture, and others, we successfully updated and implemented the new tutorials and conducted a user experience assessment project. This article explores learning theories, reflects on their actualization within the video learning objects of the new tutorial, and examines students' responses to the redesigned tutorial.

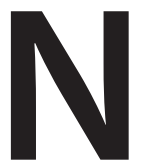

early all academic libraries offer online tutorials to assist users in understanding library resources and services. Construction and maintenance of these tutorials is a time-consuming and complex enterprise. Minor revisions to the tutorials are made throughout the academic year as frequent changes to library services, databases, and procedures require. Over the last several years, however, instruction librarians at Washington State University (WSU) reserved summers for the major revision of online tutorials and other online instructional tools. One of the most used set of tutorials, the "online tours," had been revised many times by rewriting text and updating screenshots or graphics. The set of tours was designed for two audiences-for students of the native Pullman, Washington, campus and for distance students enrolled in the "WSU Online" campus. Links to the tours have been available through the libraries' website, LibGuides, and have seen extensive use as an embedded component of UCOLL 300, the libraries' credit-bearing information literacy course.

Designed almost a decade ago, the original "tours" used HTML frames to provide a linear yet interactive environment for students to learn basic library skills. These tutorials relied primarily on graphics (mostly screen shots), textual descriptions, and stepby-step instructions to help students learn about various library services and resources. Students completing the tutorial would first read such a narrative, and then navigate to its corresponding "Try Me" section where they could complete a task related to what they had just learned.

Even at the time of the original tours' construction, HTML frames were no longer widely used for webpages. Nevertheless, the advantages of using 
frames outweighed the cosmetic considerations at the time. What was gained in functionality, however, was lost in aesthetics. After one of the library's closest campus allies, the English department, expressed reservations about suggesting the tour to its freshman students-largely because of its appearance-library staff became determined to find an alternative format for the tour material that would appeal to the target audience. The old tour had become an "information dump" of important, but uninspiring, content. The task was to move from a very text-based interface to an appealing, pedagogically sound multimedia resource for students. Aesthetically, the goal was to convey movement and process to the student, in contrast to the prior static presentation of content. Otherwise, the basic goals and outline of the original online tours were still valid in that students needed to learn how to

- navigate the libraries' website;

- access and effectively search the libraries' catalog;

- find subject databases;

- access articles and books (from a distance); and

- find course reserves (from a distance).

The project concluded with an assessment of student experiences with a set of eight videos that contained the content of the tutorial and a review of how the various learning theories manifested within student responses to an assignment for a one-credit information literacy course.

This article explores the theoretical framework employed to reconstruct and revise the online tours and outlines design elements that specifically connect to the theories. A brief description of the layout and flow of the online tours is provided, followed by a discussion of the learning theories that guided the revision of the tours. The authors then move to present an assessment project focused on the user experience of the redesigned tours. Finally, discussion of the entire reconstruction process is offered, including limitations of the assessment study and future directions for continued enhancement of the tours.

\section{TECHNOLOGY AND AESTHETICS OF THE NEXT-GENERATION ONLINE TOUR}

A review of the literature confirmed the effectiveness of multimedia over text-only instructional tools in providing instruction to students. Lim and Benbasat found that the use of multimedia improved the user's comprehension of "explanative information"-or conceptual information-which leads to problem-solving over solely text-based presentation. ${ }^{1}$ Text-based instruction proved superior in conveying "descriptive" or fact-based information. Nicholson and Nicholson, in their qualitative study, revealed student perception that multimedia course components facilitated easier completion of homework tasks because they were able to review at their own pace. ${ }^{2}$

Several articles have been written discussing practical issues, such as the types and quality of software used in production, while outlining concrete steps to take in designing instructional videos. Beales, as well as Meehan and Hyland, compared screencast software and reviewed some of the more practical elements of video production. ${ }^{3}$ Koury et al. also outlined some helpful multimedia tutorial design tips based on their experiences at Idaho State University, and Farrell, Driver, and Weathers discussed their experiences in pairing multimedia tutorials with the course management software Blackboard. ${ }^{4}$ Fortunately, librarians at WSU had experience from which to draw. For several years, Library Instruction had produced various tutorials with Qarbon Viewlet software, which facilitates the production of Flash-based presentations and interactive modules. ${ }^{5}$ Most recently, WSU librarians have used Camtasia as the primary tool for producing instructional videos. ${ }^{6}$ Other software used to remake the online tour and its contents includes Microsoft PowerPoint, Adobe's Spry UI Image Slide Show, and JWPlayer.

Library literature has not fully explored the aesthetics of online training modules. Forys and Magarrell, however, discuss the importance of aesthetics in their overhaul of their "Library Explorer" online tutorial to reflect the change in their library's catalog. ${ }^{7}$ Pomales-Garcia and Liu's article explores the role that aesthetics (and other qualities) play in the learner's perception of content difficulty, degree of learner engagement ("excitement"), and satisfaction with the learning experience. ${ }^{8}$ Pomales-Garcia and Liu discuss the importance of aesthetics and their role in encouraging engagement in terms of Bloom's Taxonomy of Educational Objectives and in terms of Clark and Mayer's exploration of self-directed learning. ${ }^{9}$ Their study serves as a strong reminder of the role aesthetics plays in learning. Among their findings, Pomales-Garcia and Liu also show that the length of a tutorial is often conversely related to the learner's perception of its aesthetics and the difficulty of its content-meaning that learning modules requiring less time to review are viewed as more appealing and their content easier to grasp..$^{10}$

\section{DESIGN OVERVIEW OF THE NEXT- GENERATION ONLINE TOUR}

The shell of the revised WSU Libraries' Online Tour for Distance Students consists of six webpages, each with a left-hand column navigation menu corresponding to roughly one of the learning goals. The introductory page contains two videos that give an overview of academic libraries and introduce some basic concepts students need to understand to proceed with the rest of the tutorial. Basic instructions presented in text inform the student about how to proceed through the rest of the tutorial.

The remaining five pages share a common design (see figure 1). Toward the top of each are links to one or two short instructional videos. The title and length of the videos are provided to students. Underneath the video links, students find a short set of instructions and one or more links 


\section{FEATURE}

to activities related to what they just learned. For example, students learning to use the WSU Libraries link resolver, which appears on online catalog and database pages as a button titled "FindIt@WSU,"will watch a demonstration of how the Libraries "FindIt" button works. After this, students can try the "FindIt Activity" links, taking them to the libraries page for finding articles where they can experiment with using the "FindIt" link resolver for themselves. In this example, the links open a WorldCat article record, and students are charged with finding the full text of the two articles. In one example, the FindIt menu takes them directly to the text of the article. In the second example, the menu takes them only to the online journal page, so the student would need to drill down or search by title for the article to access the full text (see figure 1). This arrangement of the tutorial site as well as the content of the videos required not only consideration of aesthetics but also the incorporation of sound learning theory within the multimedia environment. The project gave the authors an opportunity to consider not only the theoretical underpinnings of cognitive theories but also an exercise in applying those theories effectively in this "new" medium.

\section{LEARNING THEORIES APPLIED TO THE ONLINE TOUR VIDEOS COGNITIVE THEORIES}

According to Weinstein and Acee, cognitive theories on learning "focus on cognitive variables affecting learning-what goes on in people's minds before, during, and after learning." 11 Instructional tools that address these cognitive variables, accordingly, should result in improved learning by the student. Of course, there are many layers and variations to the cognitive learning theories-and at times, they overlap and parallel one another. In this section of the article, the authors rely heavily on Sorden's 2005 article as its discussion of multimedia and instructional design provides a succinct overview to many concepts and theories that shape contemporary thought on multimedia learning. ${ }^{12}$

These theories are explored and applied to an analysis of the video tutorials in three domains: visual, auditory, and narrative.

\section{COGNITIVE LOAD THEORY}

Cognitive load theory (CLT) is based on many hypotheses about the optimal conditions for learning and how people use their senses to process information. As explained by VogelWalcutt et al., CLT asserts that optimal learning happens when the demand put on the learner's "working memory" meets his or her ability to sensually process the information presented. ${ }^{13}$ Because people process information through two channels - auditory and visual — the presentation of information (content) must be effectively managed between these channels. As Sorden notes, mismanagement of multimedia elements can overwhelm and impair the learner's capacity to

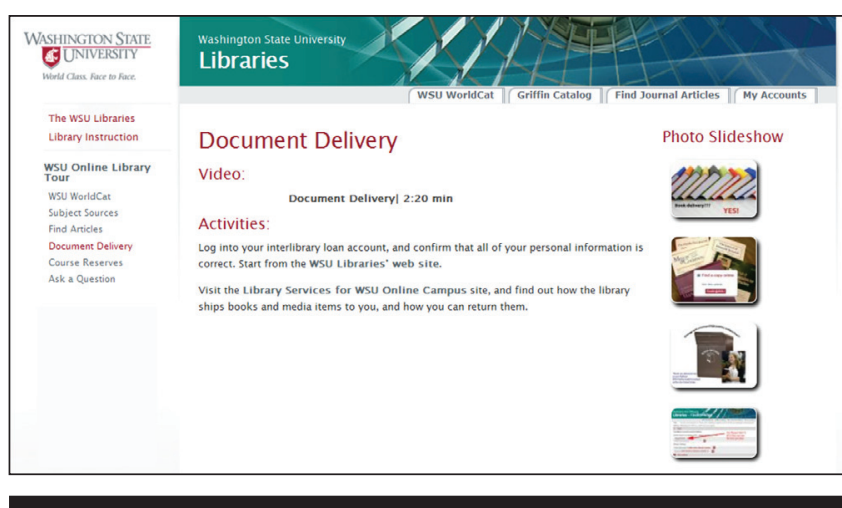

Figure 1. Sample screen from the Online Tour for Distance Students

process information by introducing distraction, redundancy, and other principles outlined by CLT theorists. ${ }^{14}$

Starting in the 1990s, an educational psychologist named Richard E. Mayer conducted a series of studies on multimedia learning with his colleagues at the University of California at Santa Barbara. These studies showed that visual and verbal media elements, or words and pictures, could be used together to promote effective learning. Multimedia learning is, in many cases, more effective than text-based learning or learning that makes use of single elements (just the visual, or just the verbal), and Mayer's work on multimedia learning has been extremely influential for the current generation of online learning tools. Mayer's cognitive theory of multimedia learning examines how the elements of multimedia, words and pictures, can be used to optimize the learner's experience by facilitating best use of the two channels. ${ }^{15}$ Timing, use of space, and cues must be carefully coordinated for "deep learning" to occur. Mayer and others have published guidelines and tips for coordinating these competing channels of information in multimedia. Mayer and Moreno write about how to encourage multimedia in ways that reduce the cognitive load, and Mautone and Mayer discuss the use of textual signals to help learners focus on the most relevant pieces of information in learning materials. ${ }^{16}$ Leeder notes libraryspecific applications of Mayer's multimedia learning theory in her discussion of teaching with videos. ${ }^{17}$

\section{THE VISUAL IN MULTIMEDIA}

Of course, the most obvious visual feature of videos is the animated nature of the medium. The ability to demonstrate process through the use of graphics and motion, and its linear nature of presenting information to learners, can be leveraged to teach both basic facts students need as well as the steps to take to fulfill their information needs. Mayer's Multimedia Principle has shown us that, "deeper learning occurs from words and pictures than from words alone." 18

Developing appeal and identification with students through the use of photographs of students using the library, 


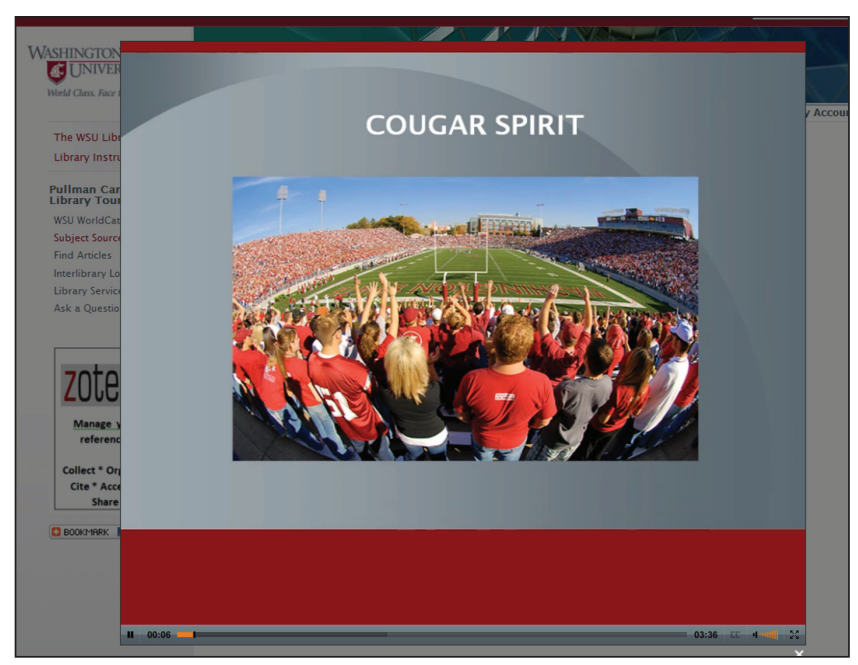

Figure 2. Sample "Cougar Spirit" image from the Online Tour for Distance Students

working on assignments, and consulting with others can also help facilitate student learning. Keller's ARCS Model for instructional motivation shows that instruction can be made appealing through, as delineated by Herbert Carson, the following elements: Attention (arousing curiosity), Relevance (connecting to a need), Confidence (make students aware of performance requirements), and Satisfaction (opportunity to use new skills).$^{19}$ Examples of how content was made visually appealing to students can be seen in the "Subject Guides and Databases," which includes images related to sports, school spirit, and course subjects.

Visual cueing through the use of arrows, highlights, and other visual means to draw attention to a specific area of the screen has been proven an effective method in reducing demand on the learner's cognitive resources. De Koning et. al. define cueing as "the addition of non-content information that captures attention to those aspects that are important in an animation (e.g. coloring, arrows)." ${ }^{20}$ Mautone and Mayer also discuss the effectiveness of this strategy, referring to it as "signaling." For example, if the student is watching a search demonstration during which the narration addresses a particular section or area of the database interface, a visual cue (such as a circle or arrow) will draw attention to the part of the interface being discussed. This way, the learner does not need to spend effort figuring out where exactly the instruction is focused, leaving that much more cognitive energy to spend on elements that are more conceptual and "deeper" to the learning.

\section{THE AURAL IN MULTIMEDIA}

Audio elements within the Online Tour videos include music clips, sound effects, and voice narration. As Crooks et al. show, these three elements can be classified in terms of how they contribute to student learning — by orienting the learner's attention to content, organizing information into manageable "chunks," or integrating these "chunks" into the larger learning objectives. ${ }^{21}$ For example, in WSU's online tutorials, the introductory audio at the beginning of each video, while empty of content, assists the learner by signaling the presence of the upcoming audio, allowing him/her time to adjust the volume. The school fight song, sound effects of radio static, or a robotic voice declaring the value of librarians in the first few seconds of the tutorials directs the learner's attention to the auditory channel and prepares them to listen to the upcoming presentation.

The most significant auditory component of the tutorials, of course, is the verbal narration, which delivers the "story" of the tutorial. Although theoretical nuances are still debated, Mayer's "modality effect," suggesting the efficacy of voice narration over written text, is widely viewed as the standard mode of tutorial delivery. The "modality effect," established that the use of animation and narration was a more effective combination in instructional multimedia than on-screen text and pictures, because it makes better use of the learner's ability to process information efficiently-thereby leaving more resources available to process the critical content of the instruction..$^{22}$

There are times, too, when associating a picture with written text as a means of reinforcing the association between them is an effective way to present information. Written text in the form of closed-captions is an option for students who may not be able to hear audio, or prefer to see the narrative text.

\section{NARRATIVE AND PROCEDURAL LEARNING}

Anderson's ACT-R (Adaptive Character of Thought) theory recognizes two types of knowledge that can be activated and that complement each other-declarative knowledge and procedural knowledge. ${ }^{23}$ Declarative knowledge is facts, terms, and specific "chunks" of information that can be built upon and aid the development of procedural knowledge. These declarative elements precede many of the demonstrational screencasts in the videos as "pre-training" sectionsintroducing potentially new terms or phrases necessary to understand the larger learning objectives. Anderson's theory proposes that these declarative "chunks" introduced early help students be less distracted or puzzled by unfamiliar facts when more complex procedures are introduced. When students are familiar with the "chunks," they can focus on the procedural aspects of learning and more easily conceptualize the broader learning objectives of the videos.

For example, in the video "Subject Guides and Databases," students are shown a list of the types of potential resources they might need to fulfill an assignment—online subject guides, librarians, databases, and the libraries' website-before they are shown how to access them or how they may be helpful. Anderson's ACT-R model of cognitive theory posits that alerting the student to these resources and naming them 


\section{FEATURE}

helps establish the declarative knowledge necessary to move toward the more practical "procedural knowledge." According to Anderson's theory, the learner can then recognize similarity in goals to be accomplished within the context of what they have learned. When they are faced with a situation that requires similar goals, they are able to connect the procedure they learned to the goal that needs to be accomplished.

Sweller's "Worked-Example Effect," as noted by Sorden, informed the design of the process-based videos, in which students are shown how to complete a research task. This theory, also based on CLT, suggests that students can benefit just as much from seeing a problem worked out, as doing the work themselves. If students are engaged in witnessing the process of problem solving, they are able to internalize the process through "self-explaining" and replicate it later. Sweller's "Completion Problem Effect" principle influenced the type of postvideo activities included in the online tours. ${ }^{24}$ For example, the "Find Articles" video focuses largely on showing students where to click on the screen to bring up the full-text of an article. Underneath the video link, students are invited to replicate this activity on their own using examples set up for them. The majority of these types of exercises or "Activities" within the tutorial require completion of a simpler one-dimensional task that reinforces the video instruction without incorporating all the possible complexities. Students are given the opportunity to "complete" a problem and gain confidence-or ask for assistance.

Keller's ARC Model of instructional motivation may also be seen within the narration in the "Request Items from WSU WorldCat" and "Online Tour Introduction" videos. These two videos address "real world" concerns of time management and the home delivery of books and media items for distance students. Students are encouraged to consider the online tour as a way to save them time in the long run by helping them practice skills they will need for later classes and be aware of policies that facilitate their access to information.

\section{ASSESSMENT OF WSU ONLINE TOUR VIDEO VISUAL ELEMENTS}

In addition to simply making the tutorials look more attractive and current, and therefore more relevant to key university audiences, the visual elements employed in the online tutorials all contribute to student learning. Five visual elements commonly employed within the videos were identified as screencasts (both still and dynamic), animation, highlighting, use of photographs, and the placement of small pieces of text on the screen. Instances of their use in the tutorial were tracked and counted, as may be seen in table 1. Each of these elements contributes to student learning and cognition, though this is most notable for screencasting, animation, and highlighting, the elements most frequently used within the WSU Online Tour video tutorials.

The authors' analysis of the visual components of the eight videos showed that screencasting was the most frequently used visual. A minority of the screencasts were still images of a website or database, but most screencasts were dynamic, demonstrating searching or navigation in action. In keeping with Mayer's Multimedia Principle, which emphases the importance of combining narration and images to
Table 1. Instances of Common Visual Elements in the Online Tour

\begin{tabular}{lc}
\hline Element & Instances \\
\hline Screencasting & 118 \\
Animation & 95 \\
Highlighting & 62 \\
Photographs & 22 \\
Text & 19 \\
\hline
\end{tabular}

facilitate deep learning, these still and dynamic screencasts of online library resources, accompanied by explanatory audio narration, provide student learners with a more readily understandable demonstration of library research techniques and processes than can be found in text, narration, or images alone. ${ }^{25}$ The aesthetic appeal of movement and live action that dynamic screencasts contribute to the tutorials is also connected to Arousal Theory, which indicates that visual or audial techniques that help peak interest may improve student learning, as discussed by Renniger, Hidi, and Krapp. ${ }^{26}$ While Mayer is skeptical of arousal theory, and for good reason, noting that extraneous images and words, or "seductive details," may in fact be barriers to student learning, he does not deny that interested students learn more effectively than non-interested students. As Clark and Mayer note, "The challenge for instructional professionals is to stimulate interest without adding extraneous material that distracts from the cognitive objective of the lesson.. ${ }^{27}$ Demonstrative screencasts, providing relevant demonstrations of research skills, while giving the feeling of action and movement, are one way to meet this challenge.

The second most frequently employed visual element in the tutorial was animation. For the purposes of this study, animation refers to any movement on the screen not part of a screencast. This includes zooming in and out on the screen, visual effects such as turning pages or rotating cubes that transition between sections of tutorial videos, and the drawing of highlighting objects (arrows, circles, etc.) on the screen. Animation, according to Clark and Mayer, may be especially effective in promoting the learning of hands-on procedures. ${ }^{28}$ In the WSU Online Tour, animation most frequently acts as another form of highlighting and sometimes acts to signal a transition from one concept to the next.

Highlighting, also known as cueing or signaling, also appears consistently throughout the tutorial. Forms of highlighting commonly found in the tutorial are the use of arrows, circles, lines, squares, and strategic lighting and shading to draw attention to specific elements of the video or image. Highlighting is a visual element used to reduce cognitive overload by helping learners focus attention on key informational elements. ${ }^{29}$ In the WSU Online Tour, highlighting is often found in conjunction with animation, so that not only do learners see a relevant part of a website circled in red, their attention is caught by watching the circling happen as they watch and listen. 
Other visual elements that were common, though used more sparingly in the videos, are photographs and key pieces of text placed on the screen. Photographs employed in the tutorials show either students engaged in studying or computer activities or well-known university landmarks. These photographs signal to student learners that tutorials are not cold and distant but relevant to them and to their peers. The placement of text on the screen, written on top of screencasts and screenshots showing library search tools and interfaces, is used during parts of the tutorial as well. These textual cues act as another form of highlighting, calling attention to important concepts being covered. On average, visual elements are employed every 3.5-5 seconds throughout the videos.

Analysis of the visual components of the videos confirmed the application of the basic multimedia principles as expressed by Mayer, as well as elements of other learning theories to appeal to students. These results encouraged WSU librarians to assess student experience with the videos contained in the Online Tour. If the tutorials had effectively communicated the learning outcomes through demonstration, would students internalize these outcomes?

\section{ASSESSMENT OF WSU ONLINE TOUR- CONNECTIONS BETWEEN THE NARRATIVE TRANSCRIPTS, STUDENT LEARNING, AND LEARNING THEORIES}

Although the Library Instruction Team (LIT) has done assessment work on the effectiveness of its tutorials, the older versions of the online tours were never part of a user experience assessment project. The LIT wanted to change direction concerning the new iteration of the WSU Online Tour, and quickly developed an assessment plan shortly after launching the new tutorial. During the 2011-2012 academic year (sixteen-week fall and spring semesters), the LIT offered two online sections of UCOLL 300-Accessing Information for Research. This one-credit, information literacy course addresses all facets of academic research and is taught by librarians. Twenty-nine students took the course and served as the participants in the tutorials assessment project. A sample size of twenty-nine students may seem small to those less accustomed to quantitative analysis, however, it is well within the normal range used and recommended for qualitative assessment. ${ }^{30}$

The UCOLL 300 environment proved very conducive to gathering feedback from a diverse group of WSU students taking distance classes. Distance courses often include older learners as well as undergraduates, and groups with varied life experiences. The students were asked to take the entire WSU Library Online Tour and then reflect on what they learned from the experience in their learning management system's (Blackboard's Angel 8.0) at WSU discussion forum. More specifically, they were asked to address several openended questions:
- Highlight at least two things you learned from the video or activity you are writing about.

- What can you now do that you couldn't before?

- Now that you have some new knowledge under your belt, how do you think you can use it for your research (for a current or future class)?

Instruction librarians applied qualitative analysis to the student comments, using ATLAS.ti to assist this process. The initial steps included coding the narrative transcripts from each video, as well as the text of the student responses to identify the informational content contained in each. These "content" codes were developed and refined through a norming process in which two librarians independently reviewed printed transcripts of the video narrations, identified significant "chunks" of information, and created the content codes to describe and define the topic matter of those information chunks. The librarians then worked together to synthesize the content codes into a consolidated list. The final list included thirty-eight content codes (see appendix).

Table 2 shows the most common content codes identified within the narrative transcripts, and table 3 shows those most common within the student responses.

Generally, students commented most on the concepts receiving the most coverage in the videos. Because the four learning outcomes could be represented by numerous content codes, the authors know quite specifically which points resonated with them the most within the learning outcomes. For example, two of the top content codes represented in the student response list, WSU WorldCat : Search and WSU WorldCat : Focus Search, both fall under the targeted learning outcome "Access and effectively search the library catalog," yet the codes reflect the different degrees of understanding and detail that students expressed in their assignment posts.

Examples of student statements coded WSU WorldCat: Search:

- "Data bases [sic] like WSU WorldCat can be used to gather information for research or study from a wide selection of sources."

- "World Cat does seem to be far superior. I had no idea you could search by article titles to find journal articles"

Examples of statements coded WSU WorldCat: Focus Search:

- "I like the different checkboxes to refine the search results to narrow down the searches."

- "Showing hints on how to narrow the search is what I found most useful."

- "Worldcat is also good for finding specific sources using the search engine, and then narrowing it down by the type of media that you are searching for."

There is only a modest correlation between the high-frequency narrative content codes and their appearance in the 


\section{FEATURE}

Table 2. Ranking of the Eight Most Prominent Content Codes within the Video Narrations (and number of occurrences) and Their Corresponding Learning Outcome

\begin{tabular}{ll}
\hline Top Content Codes Rankings (Video Narration) & Corresponding Learning Outcomes \\
\hline WSU WorldCat : Focus Search (7) & Access and effectively search the library catalog \\
\hline Request : Home Delivery (6) & Access articles and books (from a distance) \\
\hline Articles : Find It (6) & Access articles and books (from a distance) \\
\hline None : WSU Libraries' webSite (6) & Navigate library's web site \\
\hline Interlibrary : Set up account (5) & Access articles and books (from a distance) \\
& Navigate libraries' web site \\
\hline Subject : Databases (4) & Find subject databases \\
\hline Articles: Accessing (4) & Access articles and books (from a distance) \\
\hline Reserves : Access (4) & Find course reserves \\
\hline
\end{tabular}

Table 3. Ranking of the Eight Most Prominent Content Codes within Student Responses (and Percentage of Student Responses with Content Code) and Their Corresponding Learning Outcome

\begin{tabular}{ll}
\hline Top Content Codes Rankings (Student Responses) & Corresponding Learning Outcomes \\
\hline Request : Home Delivery (59\%) & Access articles and books (from a distance) \\
\hline Subject : Databases (38\%) & Find Subject Databases \\
\hline Doc Delivery : Policies (34\%) & Access articles and books (from a distance) \\
\hline WSU WorldCat : Focus Search (28\%) & Access and effectively search the library catalog \\
\hline Articles : Peer Review (28\%) & NA \\
\hline Distance : Time Management (24\%) & NA \\
\hline Interlibrary : Set Up Account (24\%) & Access articles and books (from a distance) \\
\hline WSU WorldCat : Search (24\%) & Navigate libraries' website \\
\hline
\end{tabular}

top student content codes-but it is far from a direct one to one. Only four of the top narrative codes were represented in the assignment submissions. However, because each learning outcome is represented by more than one content code, the researchers still see all four outcomes represented by the students' writing.

\section{DISCUSSION}

Having gathered data on the visual and aural structure of the video tutorials, as well as the student responses, the authors can make some conjectures about the role of the various learning theories discussed in this paper. To be sure, as learning theories are applied to any curriculum, there are overlaps as one theory borrows, extrapolates, or builds upon another. For example, the principles within Mayer's Theory of Multimedia Learning can be used to communicate a scenario using elements of Sweller's Worked Example Effect to show a student how to complete a task. If this material or instruction does not register or "stick with" the student upon assessment, is it because of faulty application of Mayer's theories, or because Sweller's theory was not adequately illustrated?
Addressing such complex issues is beyond the scope of this manuscript. However, there are observations to be made based on student responses to the assignment which prompted them to "highlight at least two things you learned from the video or activity you are writing about." Because students overwhelmingly identified elements of the videos that corresponded with most or all of the tutorial's overarching learning goals, the librarians involved in the project are satisfied that the content of the videos satisfactorily incorporated Mayer's principles. Evidence of this is taken not only from student responses, but from the extensive examination and coding of visual and aural elements within the videos.

If some of the learning objectives were well communicated and received by students to the degree that they were able to articulate them in much the same way they were presented (Request : Home Delivery; Subject : Databases; WSU WorldCat : Focus Search; and Interlibrary : Set up account), why were other topics mentioned by the students? For example, none of the videos in the Online Tour mentioned "peerreviewed articles," yet a significant percentage of students chose to discuss that in their assignment responses.

Similarly, two content codes which appeared only one to three times within the instructional videos were 
disproportionately discussed by the students: Distance : Time Management and Doc Delivery : Policies. The discussion of using the libraries to save time was only briefly mentioned in one of the videos. Distance: Time Management was discussed earlier in terms of Keller's ARC theory of motivation. It should be no surprise that saving time is a priority for a population of distance students, many of whom are balancing family and work responsibilities while taking classes.

How can librarians understand these choices within the context of the learning theories? Constructivist theory suggests that the learner is not an empty vessel to be filled with knowledge but comes with a set of experiences and knowledge that he or she builds upon. Students enrolled in the UCOLL 300 course are typically juniors and seniors-most with some experience in what their professors consider "reliable sources," e.g., peer-reviewed journals. Discussion and demonstrations of finding articles within the videos triggered their previous experiences and instruction and led them to connect to the new experiences within the videos. In terms of Keller's ARCS Model for instructional motivation, students connected to the "Relevance" of finding peer-review articles within the context of video demonstration and found "Confidence" in applying the techniques they viewed to something they could use in the future. One student wrote, "I like these databases the most because they have provided me with the most information for what I was researching. For example, with the EBSCO databases I can narrow my research options to just peer reviewed journal articles."

\section{CONCLUSION}

Our qualitative analysis of the online tour videos has produced notable results-largely because of some clear trends in the data and a solid theoretical underpinning. Appropriate audiovisual elements were successfully applied to the videos and facilitated the effective communication of the learning objectives. This is perhaps made most evident by the fact that the majority of the most frequently used content codes also appeared prominently in the student assignment responses. Those content codes that were overly represented in the student responses (including those which had no counterpart in the videos) demonstrate other learning theories that played a role in what students found significant.

Effective instruction through multimedia depends greatly on how well information is presented to the viewer. By applying the principles of Mayer's Cognitive Theory of Multimedia Learning and providing the best types (aural or visual) of stimulation at the right time, the learner's attention can be maximized and cognitive load kept in balance. Application of Mayer's principles proved effective in conveying the overall learning goals of the Online Tour videos. However, as analysis of the student responses shows, learners will also construct their own knowledge when the material elicits relevance and confidence connected to their previous experiences.

Analysis of student responses could not attribute the absence of any codes (e.g., Articles: FindIt) or the seemingly over-represented codes (e.g., Request: Home Delivery) to any difference in the multimedia components or application of Meyer's Cognitive Theory of Multimedia Learning within the videos. The authors conclude, in fact, that when the basic "laws" of multimedia presentation are followed, the effective communication and demonstration of content frees students to identify their own needs as they learn. When video content failed to translate to student comments, such as the case with Articles: FindIt, one may look at strategies to link the content to other context areas met with student enthusiasm (e.g., Request: Home Delivery) when appropriate.

As a matter of practicality, the authors could only pursue the analysis of student comments so far. One could do a more in-depth analysis of student responses by considering the role of code families rather than individual codes, for example. Despite the study's limitations, the effort and time spent on redesigning the tours based on knowledge of learning and online tutorial theory served many purposes. These efforts informed the authors' first attempts at evaluating the video tutorials. The tutorial redesign and assessment led to a more systematic overview of how multimedia tutorials are constructed, what elements are represented, and how they are represented. The authors believe the WSU Online Tour incorporates many qualities outlined by theorists to maximize learning, and the preliminary assessment work indicates there is a strong connection between the audio transcript components stressed in the tutorial and content students view as new and important. This finding, although preliminary, speaks broadly to the creation, maintenance, and assessment of multimedia tutorials across academic libraries. When ascertaining the effectiveness of tutorials, the importance of visual and aural elements should certainly be taken into account.

In terms of future directions, it is the plan of WSU researchers to engage further in student learning assessment after viewing one or more of the tutorial videos. The researchers have analyzed the students' self-assessment concerning what they learned in this study, next the authors will turn their attention to examining the tour's embedded summary activities that ask students to put into practice the information literacy skills librarians and educators desire they learn. Another avenue of future research will be exploring the ways the Online Tour impacts the quality of student research and their written materials. The tutorial is currently part of a required lesson for the online version of WSU's beginning level composition course. This kind of work would provide more evidence of the value of multimedia learning for academic library users.

Thinking beyond the WSU Online Tour, librarians can also use the assessment model outlined in this paper as one means of gauging the value of other instructional tutorials offered by the WSU Libraries. Regardless of how future assessments turn out and what they reveal, the understanding of the cognitive learning theories and how those theories manifest within library instruction tutorials will serve as an important part of the toolset with which librarians will make tutorials more effective for learning. 


\section{FEATURE}

\section{References and Notes}

1. Kai H. Lim and Izak Benbasat, "The Influence of Multimedia on Improving the Comprehension of Organizational Information," Journal of Management Information Systems 19, no. 1 (Summer 2002): 99-127.

2. Jennifer Nicholson and Darren B. Nicholson, "A Stream Runs through IT: Using Streaming Video to Teach Information Technology," Campus-Wide Information Systems 27, no. 1 (2010): 17-24.

3. Donna L. Beales, "Screencasting: Basic Knowledge for the Medical Librarian," Journal of Hospital Librarianship 11, no. 1 (2011): 87-93; David Meehan and Jack Hyland, "Video Killed the 'PDF' Star: Taking Information Resource Guides Online," SCONUL Focus 47, (2009): 23-26.

4. Regina Koury et al., "Staying on Top of Your Game and Scoring Big with Adobe Presenter Multimedia Tutorials," Journal of Library E Information Services in Distance Learning 4, no. 4 (2012): 20818; Sandy L. Farrell, Carol Driver, and Anita Weathers, "Now's the Time: Online Library Orientations," Community \& Junior College Libraries 17, no. 1 (2011): 7-14.

5. Qarbon product website, accessed March 25, 2013, www.qarbon .com.

6. Kami Convery, "Camtasia Studio," Charleston Advisor 10, no. 4 (April 2009): 12-14.

7. Marsha Forys and Kathy L. Magarrell, "A Race Against the Clock: Re-Tooling the Tutorial: What Happens When Your Library Gets a New Online Catalog?" Technical Services Quarterly 20, no. 2 (2002): 13-20.

8. Cristina Pomales-Garcia and Yili Liu, "Web-Based Distance Learning Technology: The Impacts of Web Module Length and Format," American Journal of Distance Education 20, no. 3 (2006): 163-79.

9. Ibid., 163-64, 177-78.

10. Ibid., 173 .

11. Claire Ellen Weinstein and Taylor W. Acee, "Cognitive View of Learning" in Encyclopedia of Educational Psychology, ed. Neil J. Salkind (Thousand Oaks, CA: Sage, 2008), 164-65.

12. Stephen D. Sorden, "A Cognitive Approach to Instructional Design for Multimedia Learning," Informing Science 8 (2005): 263-79.

13. J. J. Vogel-Walcutt et al., "Cognitive Load Theory vs. Constructivist Approaches: Which Best Leads to Efficient, Deep Learning?" Journal of Computer Assisted Learning 27, no. 2 (2011): 133-45.

14. Sorden, "A Cognitive Approach," 274, 276.
15. Richard E. Mayer, Multimedia Learning (New York: Cambridge University Press, 2001), 3-5, 41-62.

16. Richard E. Mayer and Roxana Moreno, "Nine Ways to Reduce Cognitaive Load in Multimedia Learning," Educational Psychologist 38, no. 1 (2011): 43-52; Patricia D. Mautone and Richard E. Mayer, "Signalling as a Cognitive Guide in Multimedia Learning," Journal of Educational Psychology 93, no. 2 (2001): 377-89.

17. Kim Leeder, "Learning to Teach through Video," in The Library with the Lead Pipe (blog), October 14, 2009, www.inthelibrarywiththeleadpipe.org/2009/learning-to-teach-through-video.

18. William R. Robinson, "Cognitive Theory and the Design of Multimedia Instruction," Journal of Chemical Education 81, no. 1 (2004): 10

19. C. Herbert Carson, "The Relationship between Hypermedia Producers' Preferred Learning Styles and the Motivational Aspects of Their Productions," Journal of Education for Library \& Information Science 47, no. 2 (2006): 106-26.

20. Björn B. de Koning, Huib K. Tabbers, Remy M. J. P. Rikers, and Fred Paas, "Attention Cueing as a Means to Enhance Learning from an Animation," Applied Cognitive Psychology 21, no. 6 (2007): 731-46.

21. Steven M. Crooks et al., "Modality and Cueing in Multimedia Learning: Examining Cognitive and Perceptual Explanations for the Modality Effect," Computers in Human Behavior 28, no. 3 (2012): 1063-71.

22. Ibid., 1063, 1065

23. John R. Anderson," Act: A Simple Theory of Complex Cognition," American Psychologist 51, (1996): 355-65.

24. Sorden, "A Cognitive Approach," 266-67.

25. Ruth C. Clark and Richard E. Mayer, E-Learning and the Science of Instruction Proven Guidelines for Consumers and Designers of Multimedia Learning (Hoboken, NJ: Wiley, 2011).

26. K. Ann Renninger, Suzanne Hidi, and Andreas Krapp, The Role of Interest in Learning and Development (Hillsdale, NJ: L. Erlbaum Associates, 1992).

27. Clark and Mayer, E-Learning and the Science of Instruction, 173.

28. Ibid., 86 .

29. de Koning et al., "Attention Cueing," 733

30. Jerome Kirk and Marc L. Miller, Reliability and Validity in Qualitative Research (Beverly Hills, CA: Sage, 1986); Doug Suarez, "Evaluating Qualitative Research Studies for Evidence based Library and Information Practice," Evidence Based Library \& Information Practice 5 (2010): 75-85.

\section{APPENDIX. ALL CURRENT CONTENT CODES AND THEIR DEFINITIONS}

\section{Article Access Family}

\section{Articles : Accessing}

Comment: The issue of finding full text articles; methods of getting to the full text of articles

\section{Articles: Other Articles}

Families (1): Article Access

Comment: The "other articles" listed at the bottom of the FindIt menu

\section{Articles : Peer Review}

Families (1): Article Access

Comment: Finding peer-review articles; the value of peer review articles to research

\section{Articles : Find It}

Families (1): Article Access

Comment: Mention of the FindIt button/or Find It

\section{Articles : Locate Citations}

Families (1): Article Access

Comment: Methods by which one can access article citations (using article indexes, WSU WorldCat)

\section{Distance Family}

\section{Distance : Services}

Families (1): Distance

Comment: Reference to the general or specific services afforded distance students 
7. Distance : Time Management

Families (1): Distance

Comment: Issues of time management as they apply to distance students and research, library services, document delivery

\section{Distance : Tuition}

Families (1): Distance

Comment: Mention of the relation between tuition and databases and other library services $\&$ value to distance student

\section{Delivery Family}

\section{Doc Delivery : Policies}

Families (1): Delivery

Comment: Mention of specific policies or mechanics of how document delivery work; display of the rules or procedures of document delivery; return postage

10. Doc Delivery : Policy Page

Families (1): Delivery

Comment: Reference to the Library Services for WSU Online Students LibGuide to find library policies for distance students

\section{Request : Home Delivery}

Families (1): Delivery

Comment: Home delivery for distance students outside of Pullman, but within the United States - books, media items

\section{Interlibrary Family}

\section{Interlibrary : ILLiad}

Families (1): Interlibrary

Comment: Specific mention of ILLiad

\section{Interlibrary : Set Up Account}

Families (1): Interlibrary

Comment: The process of accessing and setting up the ILLiad account; the interlibrary loan account; setting preferences, address, email, etc.

14. Interlibrary : Summit

Families (1): Interlibrary

Comment: Mention of Summit as a resource from which to request items

\section{Request : Interlibrary Loan}

Families (1): Interlibrary

Comment: Use of the phrase "interlibrary loan" or requesting a book not owned by WSU Libraries or Summit. Awareness of being able to obtain items that are not owned locally; WSU WorldCat books or items

16. WorldCat : Not Owned by WSU

Families (2): WSU WorldCat, Interlibrary

Comment: Noticing when WSU does not own something

\section{Reserves Family}

\section{Reserves: Access}

Families (1): Reserves

Comment: How does one access reserves material? Us-

ing Eres, a special password, link within Angel, going from citation to full text

18. Reserves : Definition

Families (1): Reserves

Comment: What are reserves? What are the different names for reserves? supplemental readings, course readings, reserves, etc.

\section{Subject Family}

\section{Subject : Access Subject Resources}

Families (1): Subject

Comment: Steps to take to access LibGuides or subject databases, where to click, how they are organized within the library website, how to get to them

\section{Subject : Database information}

Families (1): Subject

Comment: Understanding what information one can find out about a database, what it contains

\section{Subject : Databases}

Families (1): Subject

Comment: Awareness of specific subject databases by naming specific ones; listing or mentioning a database because of its academic focus or use for searching disciplinary information

\section{Subject : Identify Need}

Families (1): Subject

Comment: Looking for resources based on academic discipline, academic subject. Recognizing that a resource based within a subject discipline is needed and probably exists

\section{Subject : Librarian}

Families (1): Subject

Comment: Librarian as a resource for information, a "subject resource" 


\section{FEATURE}

\section{Subject : Subject Resources}

Families (1): Subject

Comment: Subject resources in general; understanding what subject resources are; academic disciplines, databases, people, LibGuides

\section{WSU WorldCat family}

25. WorldCat : Access

Families (1): WSU WorldCat

Comment: Finding the database WSU Worldcat from the libraries' home page

\section{WorldCat : Find Citations}

Families (1): WSU WorldCat

Comment: Search results, results screen, understanding the citations, recognizing citations

27. WorldCat : Focus Search

Families (1): WSU WorldCat

Comment: Methods to focus a search such as limiting with facets, adding keywords to a search, Boolean

\section{WorldCat : Material Type}

Families (1): WSU WorldCat

Comment: Description of the types of items one might get from WSU Worldcat (and potentially other databases); books, video, audio, art, articles, etc.

\section{WorldCat : Not Owned by WSU}

Families (2): WSU WorldCat, Interlibrary

Comment: Noticing when WSU does not own something
30. WorldCat : Request Item Families (2): Delivery, WSU WorldCat

Comment: Process of requesting item from different WSU campus, Summit, interlibrary loan (WSU WorldCat books); using the Request Item button

31. WorldCat : Search

Families (1): WSU WorldCat

Comment: Search strategies in the search box; ways of creating a search query using truncation, Boolean

\section{NO FAMILY}

\section{WSU Libraries Website}

Comment: Reference to the libraries' home page or URL

33. Google or Google Scholar

Comment: Mention of Google Scholar, use of Google Scholar

34. Griffin

Comment: Mention of Griffin; use of Griffin. (never mentioned in the tutorials)

35. Already knew from other class

36. Already used in another school

37. Peer review (general reference to "peer-reviewed resources" generally, not articles specifically

\section{Post tutorial exercise}

